\title{
Letter to the editor. Virological analysis of fatal influenza cases in the United Kingdom during the early wave of influenza in winter 2010/11
}

F Baldanti (f.baldanti@smatteo.pv.it) ${ }^{1}$, A Zanetti²

1. Molecular Virology Unit, Fondazione IRCCS Policlinico San Matteo, Pavia, Italy

2. Department of Public Health, Microbiology and Virology, University of Milan, Milan, Italy

To the editor: In response to the paper by Ellis et al. [1], published in Eurosurveillance Volume 16, issue 1, we would like to make a few observations.

D222G/N substitutions in the haemagglutinin of influenza $A\left(\mathrm{H}_{1} \mathrm{~N}_{1}\right) 2009$ strains have been associated with increased virulence [2-4].

An enhanced binding affinity of the mutated haemagglutinin to the $a-2,3$ sialic acid receptor rather than to the a-2,6 sialic acid receptor has been postulated to be the basis of the increased virulence of D222G/N mutants [3]. The a-2,3 sialic acid receptor is present at higher density on the surface of the cells of the lower respiratory tract tissues whereas the $a-2,6$ sialic acid receptor is present at higher density on the surface of cells of the upper respiratory tract tissues.

In surveillance reports from different countries, the overall presence of such mutants ranged from $2.0 \%$ to $5.6 \%$, while it was significantly higher (up to $22.9 \%$ ) in severe or in fatal cases [2-4]. Interestingly, the paper by Kilander et al., analysing both nasal swabs and bronchoalveolar lavage, showed the highest rate of $\mathrm{D} 222 \mathrm{G} / \mathrm{N}$ mutants in patients with severe and fatal infections [2]. In a multicenter study, we analysed paired nasal swabs and bronchoalveolar lavage samples from patients admitted to intensive care units for mechanical ventilation or extracorporeal membrane oxygenation. The samples were compared with samples from patients with pneumonia not requiring mechanical ventilation and from community patients. Our data showed that $\mathrm{D} 222 \mathrm{G} / \mathrm{N}$ mutants were more frequently detected in lower respiratory tract secretions than in secretions from the higher respiratory tract [5]. In addition, by combining data from nasal swabs and bronchoalveolar lavage samples, the frequency of $\mathrm{D} 222 \mathrm{G} / \mathrm{N}$ mutants in patients with severe infections increased to $43.0 \%$, as compared to $7.8 \%$ and $0 \%$ in patients with moderate and mild infections, respectively [5]. In agreement with the pathogenetic hypothesis considering the lower respiratory tract as the more favorable environment for replication of such mutants, viral RNA levels were significantly higher in bronchoalveolar lavage samples than in nasal swabs [5].

Ellis et al. reported that almost all viruses derived from fatal and non-fatal cases analysed (39/41) in the United Kingdom during the early wave of the 2010/11 influenza winter season showed the wild-type 222D haemagglutinin residue [1]. Thus, in the paper by Ellis et al., severe and fatal influenza cases were not associated with the emergence of $\mathrm{D} 222 \mathrm{G} / \mathrm{N}$ mutants, even though the role of other aminoacid substitutions remains to be determined [1]. The authors of this study do not specify the type of clinical samples used for analysis. In the case they used nasal swabs only, on the basis of the abovereferenced studies, the rate of $\mathrm{D} 222 \mathrm{G} / \mathrm{N}$ mutants might have been underestimated.

For a better understanding of the mechanisms of influenza A pathogenicity and the epidemiology of severe and fatal events, the analysis of bronchoalveolar lavage specimens in parallel with nasal swab specimens from patients admitted to intensive care units for severe infections should be envisaged. Additionally, a post-mortem analysis of tissues and/or secretions from the lower respiratory tract from deceased patients, in the event they had not been previously analysed, is important.

\section{References}

1. Ellis J, Galiano M, Pebody R, Lackenby A, Thompson C, Bermingham A, et al. Virological analysis of fatal influenza cases in the United Kingdom during the early wave of influenza in winter 2010/11. Euro Surveill. 2011;16(1):pii=19760. Available from: http://www.eurosurveillance.org/ViewArticle. aspx?Articleld $=19760$

2. Kilander A, Rykkvin R, Dudman SG, Hungnes O. Observed association between the HA1 mutation $\mathrm{D}_{222 \mathrm{G}}$ in the 2009 pandemic influenza $A\left(\mathrm{H}_{1} \mathrm{~N}_{1}\right)$ virus and severe clinical outcome, Norway 2009-2010. Euro Surveill. 2010 Mar 4;15(9)pii: 19498. Available from: http://www.eurosurveillance.org/ViewArticle. aspx?Articleld $=19535$ 
3. Mak GC, Au KW, Tai LS, Chuang KC, Cheng KC, Shiu TC, et al. Association of D222G substitution in haemagglutinin of 2009 pandemic influenza $A\left(\mathrm{H}_{1} \mathrm{~N}_{1}\right)$ with severe disease. Euro Surveill. 2010;15(14):pii=19534. Available from: http://www. eurosurveillance.org/ViewArticle.aspx?Articleld=19534

4. Puzelli S, Facchini M, De Marco MA, Palmieri A, Spagnolo D, Boros S, et al. Molecular surveillance of pandemic influenza $A\left(\mathrm{H}_{1} \mathrm{~N}_{1}\right)$ viruses circulating in Italy from May 2009 to February 2010: association between haemagglutinin mutations and clinical outcome. Euro Surveill. 2010 Oct 28;15(43)pii: 19696. Available from: http://www.eurosurveillance.org/ViewArticle. aspx?Articleld $=19696$

5. Baldanti F, Campanini G, Piralla A, Rovida F, Braschi A, Mojoli $F$, et al. Severe outcome of influenza $A / H_{1} N_{1} / 09 v$ infection associated with $222 \mathrm{G} / \mathrm{N}$ polymorphisms in the haemagglutinin: a multicentre study. Clin Microbiol Infect. 2010 Oct 14. doi: 10.1111/j.1469-0691.2010.03403.x. [Epub ahead of print]. 